\title{
The Effect of Tryptophan Analogs on the Induced Synthesis of Maltase and Protein Synthesis in Yeast
}

\section{Harlyn Halvorson, ${ }^{1}$ S. Spiegelman ${ }^{2}$ and R. L. Hinman ${ }^{3}$}

From the Department of Bacteriology, University of Michigan, Ann Arbor, Michigan; and the Department of Bacteriology, University of Illinois, Urbana, Illinois

Received August 20, 1954

\section{INTRODUCTION}

Previous studies (1-3) on the induced synthesis of $\alpha$-glucosidase in nondividing suspensions of Saccharomyces cerevisiae have indicated that the process involves the de novo formation of protcin from the free amino acid pool. The data led to the conclusion that the first stable intermediate between the free amino acids and the fully formed enzyme molecule was of such complexity that its synthesis demanded the simultaneous availability of virtually all the various free amino acid pool components. Much of the information obtained in the course of these studies stems principally from the use of halogenated derivatives of phenylalanine. In view of the importance of the conclusions drawn, it was of interest to subject them to further tests with effective analogs of other amino acids.

In looking for utilizable antagonists, two principles were kept in mind. The compounds should be analogs of free amino acid pool components which are present in relatively low concentrations. Further, it should be possible to demonstrate the existence of a competitive interaction with the corresponding homologs. The results reported in the present paper

1 This work was supported in part by a grant from the Horace Rackham School of Graduate Studies, University of Michigan.

- Supported by a grant from the National Cancer Institute of the U. S. Public Health Service.

s Present address: Department of Chemistry, University of Iowa, Iowa City, Iowa. 
were obtained with tryptophan antagonists which fulfil both of these requirements.

\section{Methods and Materials}

\section{A. Strain Used and Conditions of Culture}

The yeast strain used was strain $\mathrm{K}$, a diploid representative of $S$. cerevisiae. Cells were grown in a complete medium prepared by adding the following to 11 . of water: $5 \mathrm{~g}$. peptone (Difeo), $2.5 \mathrm{~g}$. ycast extract, $6.0 \mathrm{ml}$. 60\% sodium lactate, 60 g. glucose, 6 g. $\left(\mathrm{NH}_{4}\right)_{2} \mathrm{SO}_{4}, 2$ g. $\mathrm{KH}_{2} \mathrm{PO}_{4}, 0.25$ g. $\mathrm{CaCl}_{2}$, and 0.25 g. $\mathrm{MgSO}_{4} \cdot 7 \mathrm{H}_{2} \mathrm{O}$. Cultures were incubated in standing cotton-plugged $250-\mathrm{ml}$. Erlenmeyer flasks containing $75 \mathrm{ml}$. of medium. After $12 \mathrm{hr}$. of incubation at $30^{\circ} \mathrm{C}$., the log-phase cultures were harvested by centrifugation, washed twice with chilled water, and suspended in cold buffer to a density of $2.84 \mathrm{mg}$. dry weight $/ \mathrm{ml}$. as measured with a calibrated Klett-Summerson photoelectric colorimeter.

\section{B. Conditions of Induction and the Measurement of Enzyme Synthesis and Growth}

Effects on growth were carried out in Burkholder's (4) synthetic medium modified by the omission of asparagine, the increase of $\left(\mathrm{NH}_{4}\right)_{2} \mathrm{SO}_{4}$ to $8 \mathrm{~g} . / 1$., and the inclusion of $5.9 \mathrm{~g}$. succinic acid/l. to increase buffering capacity at pH 4.5. Unless otherwise specified, glucose, at a level of $3 \%$, was the major carbon source.

Inductions were conducted with cells suspended in the above synthetic medium in which the nitrogen source was omitted and maltose was substituted for glucose. Amino acids and amino acid analogs were adjusted to $\mathrm{pH} 4.5$ in water before their addition to the inducing medium.

The course of aerobic enzyme synthesis was followed by the usual two-cup method (5), the level of enzyme being proportional to the $Q_{\mathrm{CO}_{2}}{ }^{2}$ above the endogenous level. Manometric measurements were carried out with conventional Warburg equipment at $30^{\circ} \mathrm{C}$. Anaerobic conditions were established by flushing with nitrogen.

The enzyme content of intact cells was further checked by two methods. The enzyme content of intact cells was stabilized by ultraviolet irradiation, and the anaerobic maltose-splitting capacity was measured manometrically (6). The enzyme activity of the dried cells was also measured by the rate of glucose released using a maltose-negative yeast strain, Torula monosa (1).

\section{Collection and Analysis of Free Amino Acid Pools}

The free amino acid pools were collected by the procedures devised by Gale (7). Their components were analyzed by the use of specific amino acid decarboxylases (8) and paper strip chromatography (9). The details of the applications of these methods to yeast have been described previously $(1,0)$.

\section{Chemicals}

The maltose used was Merck's maltose, further purified by recrystallization from $50 \%$ alcohol. 
Purified amino acids from the Nutritional Biochemical Corporation were used in this study. The analogs employed were generously supplied by Dr. H. R. Snyder, Department of Chemistry, University of Illinois.

\section{Experimental Results}

\section{A. Inhibition of Maltase Synthesis and Growth by Tryptophan Analogs}

The effect of these analogs on the induced synthesis of maltase by yeast is shown in Fig. 1 and the per cent inhibition of enzyme synthesis is summarized in Table $I$. It is clear from the data that the presence of these analogs results not only in a reduced rate of enzyme formation but also in an increase in the lag period. These findings are in agreement with previous experiments employing analogs of other amino acids (1).

In the case of the most effective antagonist, DL-tryptazan, the lag period is increased from 35 to $100 \mathrm{~min}$. and the rate of enzyme synthesis is decreased to $33 \%$ of the control. The corresponding growth rates of these cells in the presence and absence of $0.005 M$ tryptazan are 0.0094 and 0.0162 , respectively.

Analysis for amino nitrogen of the supernatants from cells incubated in the presence of $0.01 M$ DL-tryptazan (14) showed no detectable loss
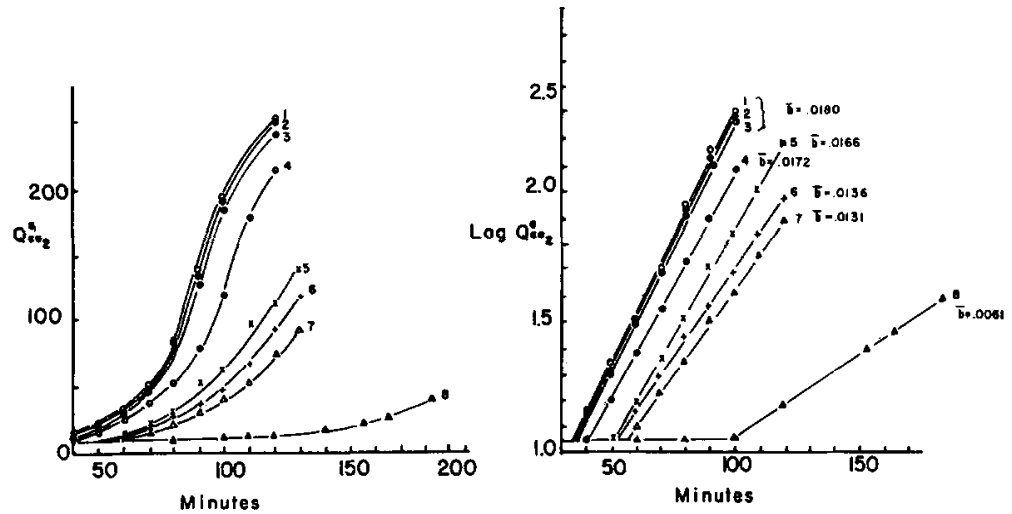

Fig. 1. The effect of tryptophan analogs on the induced synthesis of maltase. Maltose at a level of $3 \%$ and analogs at a level of $0.01 M$ were added at zero time. Enzyme was measured continually by the two-cup method and expressed as $Q_{\mathrm{CO}_{2}}{ }^{\circ}$. The right-hand curve represents a semilogarithmic plot of those on the left. The $\bar{b}$ values represent the slopes of the linear portions of the corresponding curves. The numbers indicate the following additions to the flasks: (1) none, (2) homotryptophan, (3) 6-methyltryptazan, (4) 4,6-dimethyltryptophan, (5) 4-methyltryptophan, (6) 5-methyltryptophan, (7) 6-methyltryptophan, and (8) tryptazan. 
of DL-tryptazan from the medium. In addition, the DL-tryptazan was reisolated, recrystallized, and identified by comparison with a known pure sample of DL-tryptazan.

\section{B. Demonstration that DL-Tryptazan Inhibits Enzyme Synthesis}

DL-Tryptazan did not exhibit any detectable effect upon either the fermentation or utilization of glucose or maltose by fully induced cells.

A more direct demonstration that tryptazan actually inhibited the synthesis of the maltase enzyme was achieved by enzyme assay of dried cell preparations. Enzyme content was stabilized by irradiating the cell suspension (6) and "fast dried" preparations were made. The results in Table II clearly indicate that tryptazan prevents the appearance of enzyme activity in the intact cell by preventing its formation.

\section{Reversal of Tryptazan Inhibition by Amino Acids}

The ability of purified amino acids to reverse the inhibition of maltase synthesis by DL-tryptazan was examined. All of the 21 amino acids in addition to glutamine, asparagine, and ammonia were included. The only compound which gave complete reversal was DL-tryptophan. Of the remaining compounds tested, only L-tyrosine was detectably effective.

Gunsalus (personal communication) observed that DL-tryptazan inhibits the activity of the tryptophanase enzyme in Escherichia coli. DLTryptazan would appear, however, not to be exerting its effect in this manner in ycast, since no detectable tryptophanasc activity is observed in either intact or cell-free extracts of $S$. cerevisiae.

The inhibiting effect of DL-tryptazan concentrations on the synthesis of maltase and the reversal of this inhibition by DL-tryptophan is shown in Figs. 2 and 3. A maximal inhibition of $72 \%$ is observed in the presence of $0.010 M$ DL-tryptazan. Inspection of Fig. 3 reveals an inhibition index (ratio of DL-tryptazan: DL-tryptophan giving half maximal inhibition) of about 20 .

A competitive inhibition requires (15) that the degree of inhibition established be determined not by the level of antagonist used, but by the molar ratio of antagonist to metabolite. It is seen from the data summarized in Table III that, within experimental error, the competitive situation is satisfied for three different ratios of DL-tryptazan to DLtryptophan. 


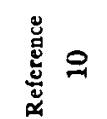

o $\exists$

0

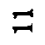

$+$
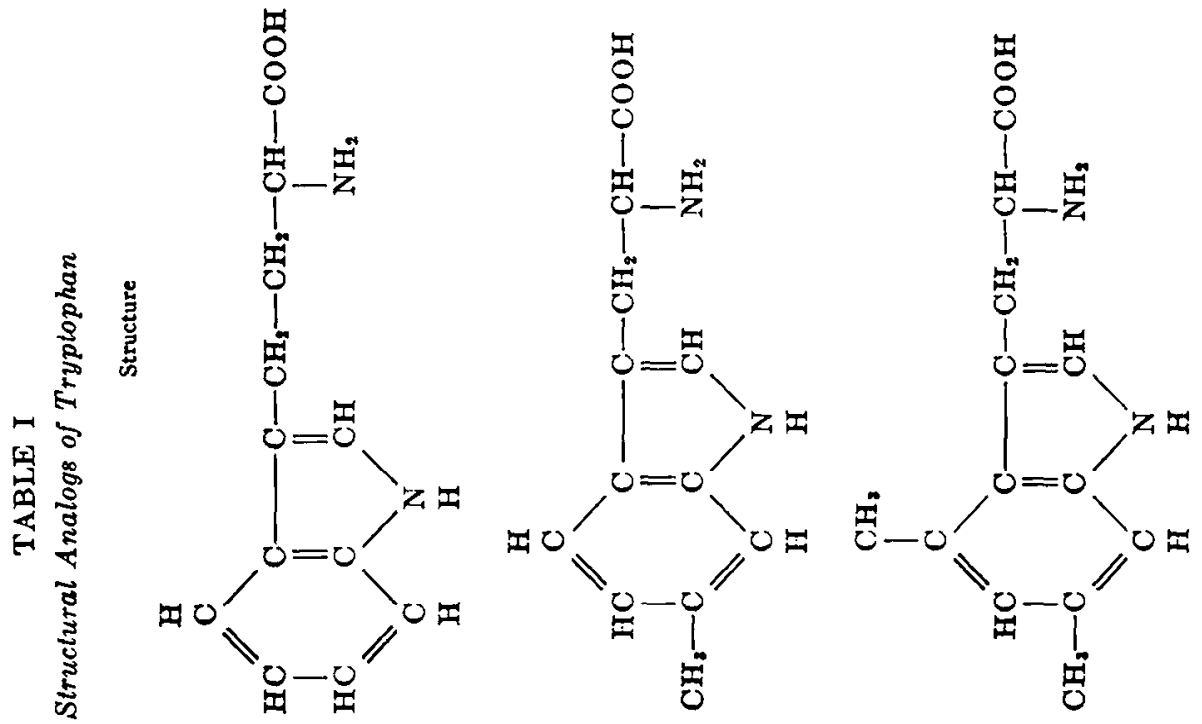

总
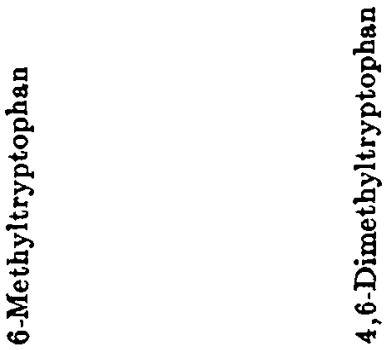

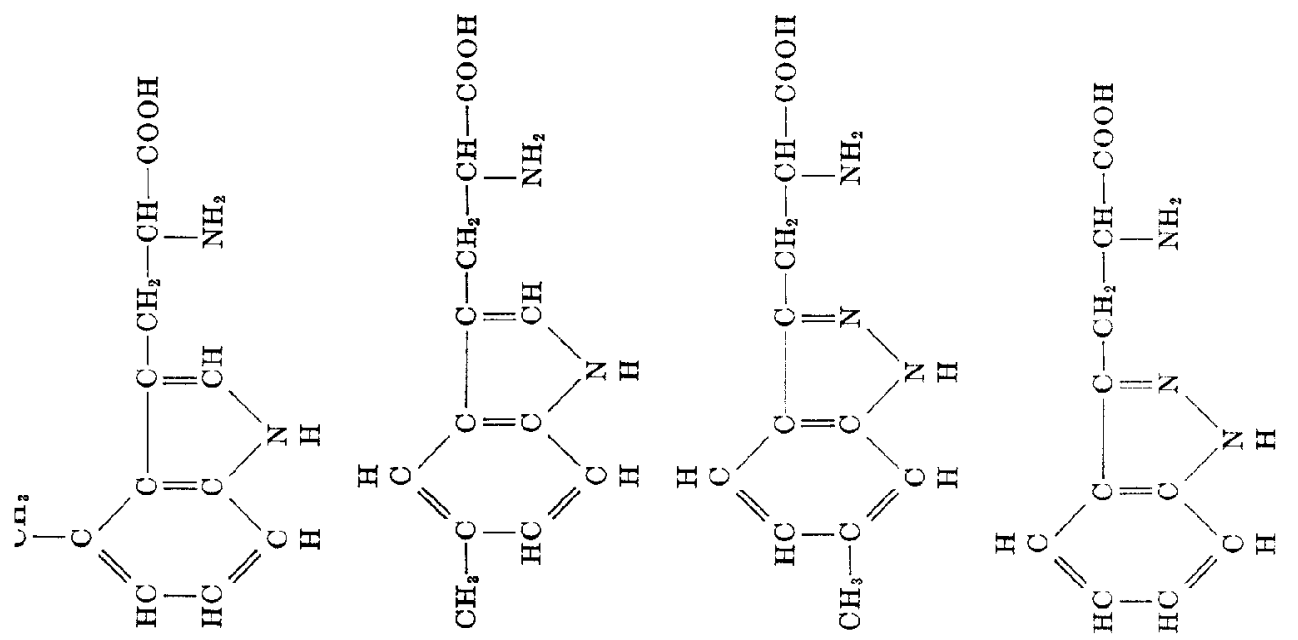


\section{TABLE II}

\section{Direct Demonstration of Inhibition of Enzyme Synthesis by Tryptazan}

Cells were incubated aerobically to maltose for $90 \mathrm{~min}$. at $30^{\circ} \mathrm{C}$. in the presence and absence of $0.01 \mathrm{M}$ tryptazan. At the end of this period, cells were centrifuged and washed, and their enzyme content was stabilized by exposure to ultraviolet light irradiation. The enzyme content of the intact cells was determined manometrically under anaerobic conditions. The enzyme content of dried cells was estimated on "fast dried" preparations from aliquots of the same samples by the Torula procedure (1).

\begin{tabular}{l|c|c}
\hline \hline \multirow{2}{*}{ System } & \multicolumn{2}{|c}{$Q_{\mathrm{co}_{2} \mathrm{~N}}$} \\
\cline { 2 - 3 } & Control & Tryptazan \\
\hline Intact cells & 180 & 10 \\
Dried cells & 184 & 11 \\
\hline
\end{tabular}

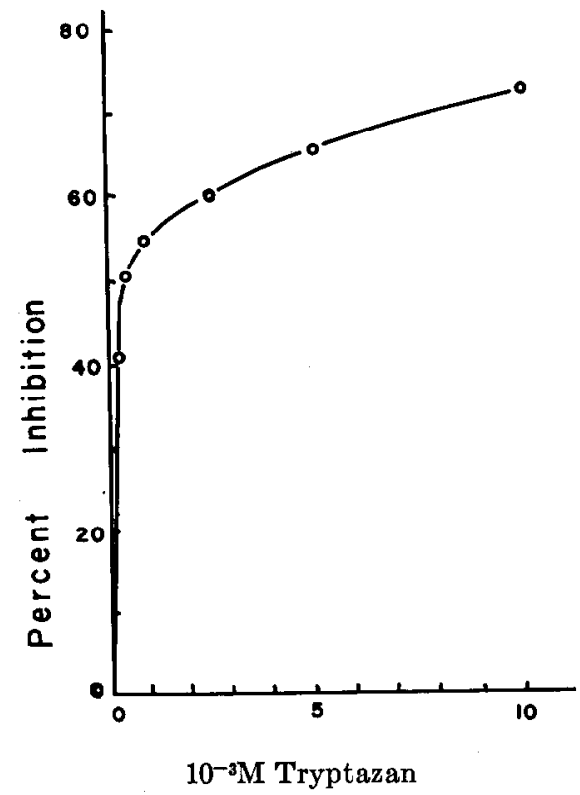

FIG. 2. Inhibition of maltase synthesis by tryptazan. The induced synthesis of maltase was followed manometrically by the two-cup method in the presence of varying concentrations of tryptazan. The rates of synthesis were obtained from the slopes of the semilogarithmic plots. The control rate was set at 100 . 


\section{Inhibition of Net Utilization of the Free Amino Acid Pool by DL-Tryptazan}

The work of numerous investigators has shown that during glucose metabolism in the absence of exogenous nitrogen, the free amino acid pool of yeast is incorporated into cellular proteins $(3,16,17)$. During such an $\mathrm{N}$ starvation of this sort, all components of the free amino acid pool suffer depletion. It has been shown $(2,3)$ that under certain conditions one can follow the behavior of the pool in terms of one or two of its components. Glutamic acid and lysine are particularly convenient, since they are present in relatively large amounts and are readily amenable to quantitative estimation by means of specific decarboxylases.

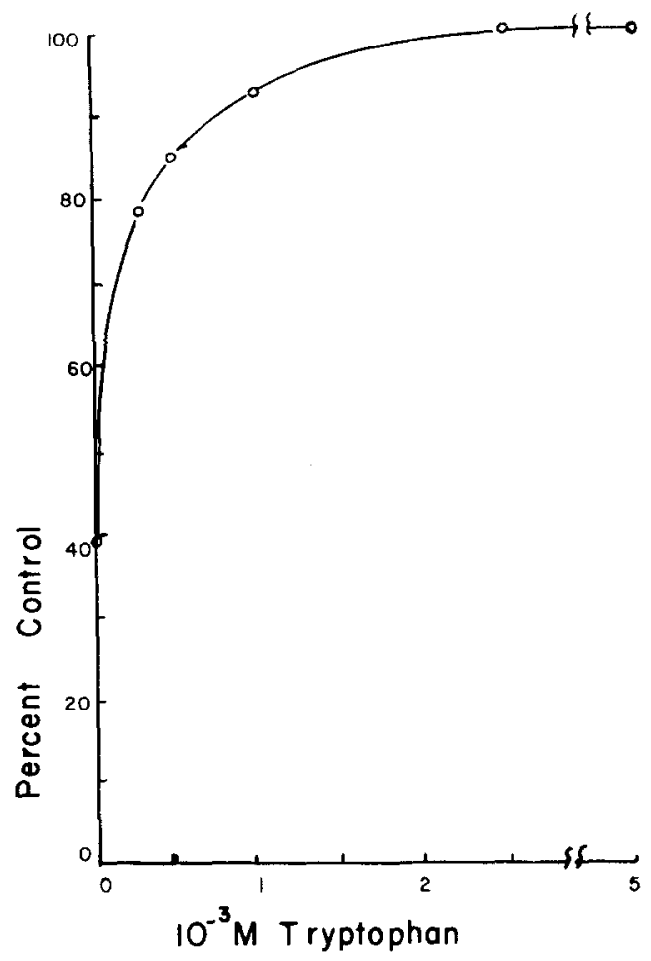

FIG. 3. Reversal of tryptazan inhibition by tryptophan. Maltase synthesis was measured manometrically as $Q_{\mathrm{Co}_{2}}{ }^{0}$ in the presence of $0.005 \mathrm{M}$ tryptazan and varying concentrations of tryptophan. The rate of induction was determined from the slope of the linear portion of the curves obtained in a semilogarithmic plot against time. The control rate was set at 100 . 


\section{TABLE III}

\section{Competitive Inhibition of Tryptophan by Tryptazan}

Maltose induction was carried out in the presence of $3 \%$ maltose and various concentrations of tryptophan and tryptazan. In each case the induction rates were calculated from the slopes of the linear portions of the curves in a semilogarithmic plot of $\mathrm{Q}_{\mathrm{CO}_{2}}{ }^{0}$ against time.

$\begin{array}{ccccc}\text { I/S } & \begin{array}{c}\text { I } \\ \text { Tryptazan }\end{array} & \begin{array}{c}S \\ \text { Tryptophan }\end{array} & \dot{b} & \text { Per cent control } \\ - & - & - & 0.0206 & 100 \\ 20 & 0.010 & 0.00050 & 0.0173 & 84 \\ & 0.005 & 0.00025 & 0.0171 & 83 \\ 50 & & & & \\ & 0.010 & 0.0020 & 0.0109 & 53 \\ & 0.005 & 0.0010 & 0.0104 & 51 \\ 100 & & & & \\ & 0.010 & 0.0010 & 0.0085 & 41 \\ & 0.005 & 0.0005 & 0.0084 & 41\end{array}$

The ability of tryptazan to inhibit the utilization of nonhomologous pool components was examined. A typical experiment of this nature may be detailed. Log-phase cells were harvested, washed twice, and suspended in $\mathrm{N}$ - and carbohydrate-free Burkholder's medium to a density of $2.84 \mathrm{mg}$. dry weight/ml. The suspension was divided into three $100-\mathrm{ml}$. portions, one of which was used for a zero time-free amino acid pool sample. Glucose was added to the other two to a final level of $3 \%$. DLTryptazan, at a final concentration of $0.02 M$, was added to one of these,

\section{TABLE IV}

The Effect of $0.02 M$ Tryptazan on the Utilization of Glutamic Acid in the Free Amino Acid Pool

Suspensions of washed, log-phase cells (1) were nitrogen-starved for $70 \mathrm{~min}$. at $30^{\circ} \mathrm{C}$. in nitrogen-free synthetic medium containing $3 \%$ glucose in the absence $(2)$ and presence (s) of $0.02 M$ tryptazan. The glutamic acid and lysine content of the free amino acid pools was analyzed by the decarboxylase method.

\begin{tabular}{c|l|c|c}
\hline \multirow{2}{*}{ Flask } & \multicolumn{2}{|c|}{ Cells } & \multicolumn{2}{c}{$\mu M / 100 \mathrm{mg}$ dry cells } \\
& & Glutamic acid & Lysine \\
\hline 1 & Control cells & 10.5 & 10.6 \\
2 & 70 min.-starved control & 2.1 & 3.4 \\
3 & 70 min.-starved $0.02 M$ tryptazan & 9.0 & 8.8 \\
\hline
\end{tabular}


the other serving as a control. The two suspensions were then shaken at $30^{\circ} \mathrm{C}$. for $70 \mathrm{~min}$. by means of a rotary shaker. Subsequently, the cells were centrifuged, washed, resuspended to a final volume of $10 \mathrm{ml}$. in water, and placed in a boiling water bath for $15 \mathrm{~min}$. After cooling, the samples were centrifuged, and the supernatants were analyzed for amino acids. The glutamic acid and lysine pool levels in these samples were determined manometrically using specific decarboxylases (8). The results obtained are shown in Table IV. During the $70-\mathrm{min}$. starvation period, the glutamic acid and lysine levels were reduced to 20 and $32 \%$, respec-
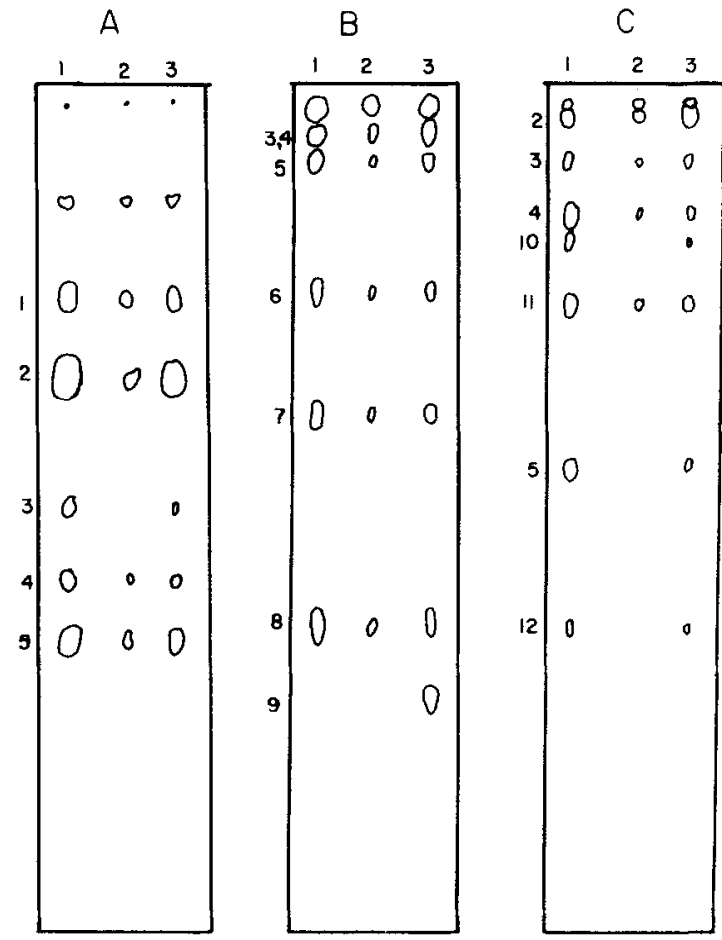

Fig. 4. The effect of tryptazan on the net utilization of the free amino acid pool. Free amino acid pools were prepared from control cells (1), cells starved for $70 \mathrm{~min}$. in the presence of $6 \%$ glucose (2), and $6 \%$ glucose plus $0.02 M$ tryptazan (3). Three solvent systems were employed: phenol for $24 \mathrm{hr}$. (A), o-cresol for $24 \mathrm{hr}$. $(B)$, and $m$-cresol for $40 \mathrm{hr} .(C)$. The numbers indicate the following identified components: (1) aspartic acid, (2) glutamic acid, (3) serine, (4) glycine, (5) glutamine plus alanine, (6) tyrosine, (7) valine, (8) leucine plus isoleucine, (9) tryptazan, (10) threonine, (11) lysine, and (12) valine plus arginine. 
tively, of their original levels. In the presence of nu-tryptazan, however, the glutamic acid and lysine pool levels were 86 and $83 \%$ of their initial concentrations.

In order to see whether the behavior of lysine and glutamic acid was representative of the other free amino acid pool components, the three samples were analyzed by paper chromatography (9). The results are shown in Fig. 4. Inspection of these chromatograms shows that DLtryptazan does retard the incorporation of all free pool components.

Repeated analysis would appear to indicate that the utilization of serine, glycine, and threonine is less severely affected than other pool components by the presence of tryptazan. This may well be a reflection of their involvement in the synthesis of heterocyclic compounds.

\section{Discussion}

It is of interest to note that an attempt was made in the course of the present investigation to determine whether the inhibition of protein synthesis observed with the analogs examined was generally attainable with gram-positive organisms. Accordingly, the effect of $0.01 M$ DL-tryptazan on the growth of a series of bacilli strains in a synthetic medium (18) was determined. Bacillus fulminans and Bacillus subtilis C-4 were inhibited, whereas no effects were observed on the K-15 or K-21 strains of B. subtilis, or on Bacillus cereus. All of these organisms were, however, strongly inhibited by the same concentration of DL- $p$-fluorophenylalanine. The paucity of the free amino acid pools of these organisms made it difficult to correlate the presence or absence of inhibition of growth with any possible effects on the net utilization of the free amino acid pools or on their composition.

The survey of the substituted tryptophan compounds indicates that a number of these were effective in preventing both enzyme synthesis and protein formation, as measured in terms of growth. DL-Tryptazan acts in a manner similar to DL-p-fluorophenylalanine, in that its ability to suppress enzyme synthesis is closely correlated with its effect on the utilization of the free amino acid pool. It was found that DL-tryptophan competitively reverses the DL-tryptazan inhibition. L-Tyrosine, at high levels, can partially reverse the inhibition, while all other amino acids, as well as $\mathrm{NH}_{3}$, were found to be inactive as reversal agents. The effect of L-tyrosine may be similar to that reported by Marshall and Woods (19) who observed that the inhibition exerted by 4-methyltryptophan could be reversed by L-phenylalanine, L-tyrosine, L-tryptophyl-L- 
phenylalanine, and L-tyrosyl-L-tryptophan. The latter two peptides reversed the inhibition in a noncompetitive manner.

It is evident from an examination of Table I that tryptazan is the most effective antagonist in the system being studied. Comparison with the other compounds listed in Table I illustrates the difficulty in relating the structures of the analogs in any predictive manner to their efficiency as inhibitors. Although the substitution of a methyl group at position 4 or 6 in tryptophan reduced the rate of enzyme synthesis 8 and $27 \%$, respectively, DL-4,6-dimethyltryptophan decreased this rate only $4 \%$. A more striking example is seen in the case of DL-tryptazan inhibition. The substitution of a methyl group in the 6-position virtually eliminates its effectiveness as an inhibitor, although 6-methyltryptophan itself is an inhibitor.

The ability of DL-tryptazan to inhibit the net incorporation of the identified components of the free amino acid pool, and the absence in the chromatograms of ninhydrin-reacting spots peculiar to cells incubating in DL-tryptazan, supports the conclusions derived from the earlier studies (1) employing the halogenated phenylalanines. Such results again suggest that the mechanism of protein synthesis is one which involves the simultaneous utilization of the constituent amino acids, and leads one quite naturally to adopt a template-type mechanism. The data argue against the stepwise formation of stable, small peptide fragments. It is not feasible to undertake here an extensive discussion of the recent information obtained from radioactive experiments with intact animals and tissues which have attempted to decide between the template and stepwise mechanisms (20-25).

In general, unequal labeling has been taken as an argument against, the simultaneous utilization of a common free amino acid pool and in favor of a stepwise synthesis via peptides. That this is not a necessary deduction from such data has already been pointed out by Dalgliesch (26). A more serious difficulty is introduced by the realization that the incorporation of labeled amino acids into protein need not provide us with information necessarily uniquely relevant to the question of total protein synthesis. This lack of uniqueness stems from the fact that exchange reactions between fully formed protein molecules and constituent amino acids are necessarily included in the information obtained from such tracer experiments.

That a very real difficulty exists is well illustrated by the experiments recently reported by Gale and Folkes $(27,28)$. In analogy with the re- 
sults obtained with yeast (1), these authors find that $p$-chlorophenylalanine can prevent new protein synthesis in Staph. aureus. In addition they revealed that although the presence of this analog effectively prevents the incorporation of labeled phenylalanine into protein, it has relatively little effect on the incorporation of glutamic acids. Convincing evidence is provided that the glutamic acid has indeed become a part of the protein molecules of the cell. It is evidently possible to dissociate incorporation due to net protein synthesis from that which is attributable to exchange reactions.

The existence of such phenomena raises the question of how to interpret incorporation studies. The data obtained may tell us more about the geometry of the protein molecule, in terms of exchange along its length, than about how it is put together. In any event, an estimation of the quantitative importance of exchange reactions is necessary before the data obtained in incorporation studies can be accepted as relevant to the evaluation of alternative mechanisms of enzyme synthesis.

\section{ACKNOWLEDGMENTS}

The authors wish to thank Mrs. Mary Meetsma for her assistance in these studies and Dr. E. F. Gale for the culture of Bacterium cadaveris 6578 used in the preparation of the lysine decarboxylase.

\section{Conclusions and Summary}

The induced synthesis of maltase in yeast was found to be inhibited by structural analogs of tryptophan. The most effective of these, DLtryptazan, inhibits growth, enzyme synthesis, and the utilization of the free amino acid pool. The activity of the enzyme once formed and the rate or characteristics of maltose or glucose utilization are, however, not influenced by its presence.

The inhibition can be competitively reversed by DL-tryptophan. LTyrosine was the only other amino acid found to give a partial reversal of the inhibition. A chromatographic and decarboxylase analysis of the free amino acid pool components indicate that DL-tryptazan inhibits in a parallel fashion the net incorporation of each of the components of the free amino acid pool. There was no evidence for the accumulation of peptides in the pools of cells incubaled in the presence of the analog. These results support the conclusion that the first stable intermediate formed is of such complexity as to demand the participation of a large proportion of the various amino acids present. 


\section{RFFERENCES}

1. Halvorson, H. O., and Spiegelman, S., J. Bacteriol. 64, 207 (1952).

2. Halvonson, H. O., and Spiggelman, S., J. Bacteriol. 65, 496 (1953).

3. Halvorson, H. O., ANd Spiegelman, S., J. Bacteriol. 65, 601 (1953).

4. Burk holder, P. R., Am. J. Botany 30, 206 (1943).

5. Umbreit, W. W., Burris, R. H., and Stauffer, J. F., "Manometric Techniques and Tissue Metabolism," 2nd ed. Burgess Publishing Co., Minneapolis, 1950 .

6. Spiegelman, S., and Halvorson, H. O., J. Bacteriol. 68, 265 (1954).

7. Gale, E. F., J. Gen. Microbiol. 1, 53 (1947).

8. Gale, E. F., Biochem. J. 39, 46 (1945).

9. McFarren, E. F., Anal. Chem. 23, 168 (1951).

10. Snyder, H. R., and Pilgrim, F. J., J. Am. Chem. Soc. 70, 1962 (1948).

11. Snyder, H. R., Beilfuss, H. R., And Williams, J. K., J. Am. Chem. Soc. 75, 1873 (1953).

12. Snyder, H. R., and Williams, J. K., J. Am. Chem. Soc. 76, 1298 (1954).

13. Snyder, H. R., Thompson, C. B., and Hinman, R. L., J. Am. Chem. Soc. 74, 2009 (1952).

14. Moore, S. and Strein, W. R., J. Biol. Chem. 176, 367 (1948).

15. Shive, W., Ann. N. Y. Acad. Sci. 52, 1212 (1950).

16. Rorne, P., Ph.D. thesis, University of Helsinki, 1947.

17. Bair, W., ANd Rouser, G., Federation Proc. 4, 183 (1952).

18. Stewart, B. T., and Halvorson, H. O., J. Bacteriol. 65, 160 (1953).

19. Marshall, J. H., and Woods, D. D., Biochem. .J. 51, ii (1952).

20. Anfinsen, C. B., and Steinberg, D., J. Biol. Chem. 189, 739 (1951).

21. Anfinsen, C. B., and Flavin, M., Federation Proc. 12, 170 (1953).

22. Askonas, B. A., Campbell, P. N., and Work, T. S., Biochem. J. 66, iv (1954).

23. Camprell, P. N., And Work, T. S., Biochem. J. 52, 217 (1952).

24. Campbell, P. N., and Work, T. S., Nature 171, 997 (1953).

25. Simpson, M. V., and Velick, S. F., J. Biol. Chem. 208, 61 (1954).

26. Dalgliesch, C. E., Nature 171, 1027 (1953).

27. Gale, E. F., and Folkes, J. P., Biochem. J. 65, 730 (1953).

28. Gale, E. F., and Folkes, J. P., Biochem. J. 55, 721 (1953). 